\title{
TRANSDISCIPLINARIDADE E FORMAÇÃO DE PROFESSORESINDIGENAS NA LICENCIATURA INTERCULTURAL EM RORAIMA
}

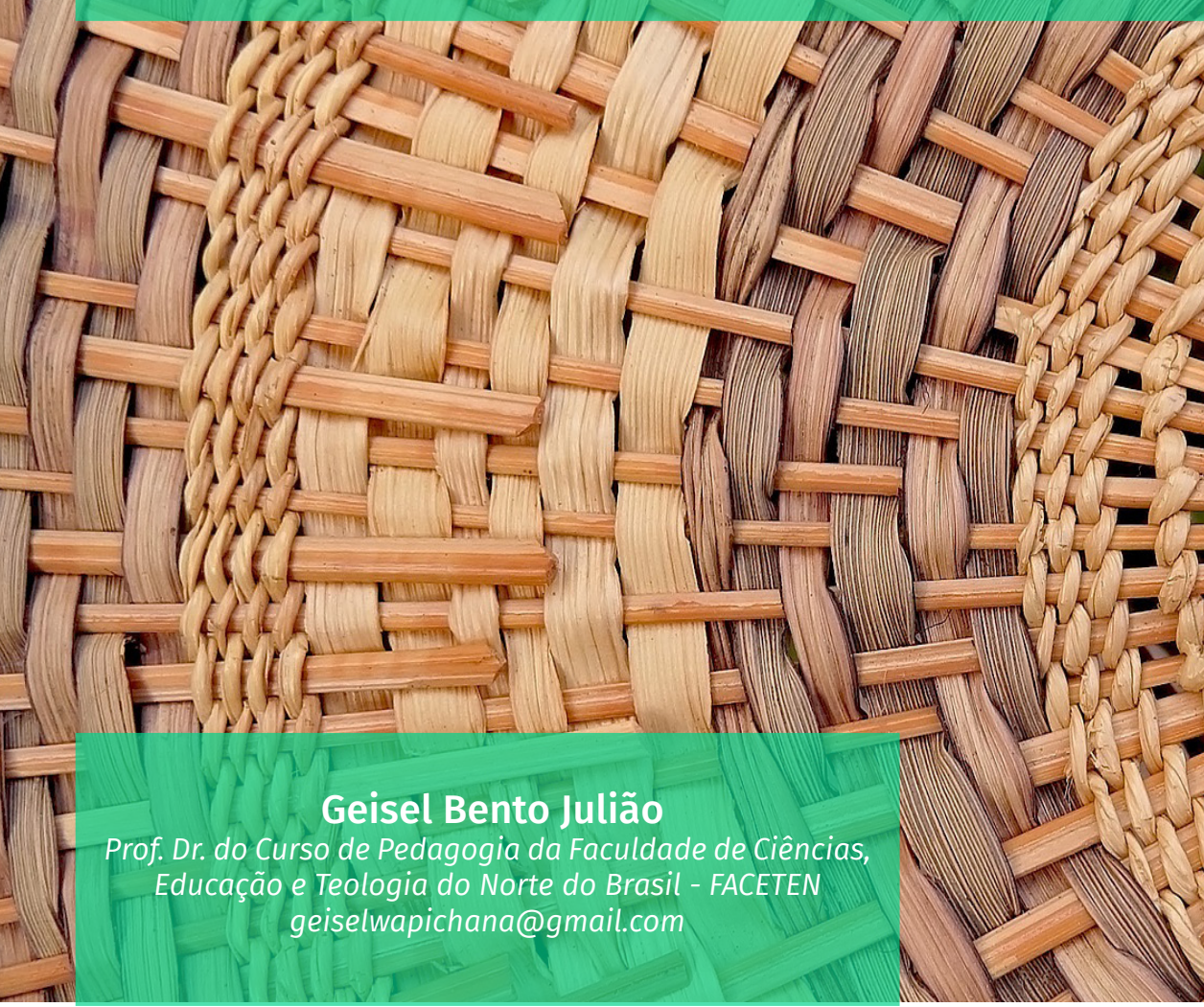

RESUMO

A desvalorização dos diferentes conhecimentos indígenas no currículo escolar é o problema que tem norteado minhas pesquisas mais recentes e que deu origem a este texto. 0 presente estudo, de cunho qualitativo, envolveu pesquisa teórica e observação de campo. Tem como objetivo apontar e descrever a transdisciplinaridade como princípio teórico-metodológico de um currículo que valoriza os diferentes conhecimentos indígenas nas diferentes dimensões da prática pedagógica. As pesquisas de campo foram realizadas na Licenciatura Intercultural da Universidade Federal de Roraima. Concluiu-se que as lideranças indígenas e os colaboradores não índios, ao construir a Licenciatura Intercultural, estabeleceram em sua proposta pedagógica princípios teóricos e metodológicos que romperam com a realidade do currículo integracionista, trazendo para o centro do processo de ensino e aprendizagem na sala de aula os diferentes conhecimentos indígenas em diálogo com os conhecimentos acadêmicos. Essa mudança tem possibilitado a construção de uma prática pedagógica diferenciada, com perspectiva crítica e libertadora, cuja característica principal é a valorização dos diferentes conhecimentos indígenas em seu currículo.

Palavras - chave: Currículo. Transdisciplinaridade. Escola Indigena. Roraima. Licenciatura Intercultural.
La desvalorización de los diferentes conocimientos indígenas en el currículo escolar es el problema que ha guiado mis investigaciones más recientes y que dio origen a este texto. El presente estudio, de cuño cualitativo, involucró investigación teórica y observación de campo. Tiene como objetivo apuntar y describir la transdisciplinariedad como principio teórico-metodológico de un currículo que valora los diferentes conocimientos indígenas en las diferentes dimensiones de la práctica pedagógica. Las investigaciones de campo se realizaron en la Licenciatura Intercultural de la Universidad Federal de Roraima. Se concluyó que los liderazgos indígenas y los colaboradores no indios, al construir la Licenciatura Intercultural, establecieron en su propuesta pedagógica principios teóricos y metodológicos que rompieron con la realidad del currículo integracionista, trayendo al centro del proceso de enseñanza y aprendizaje en la sala de clase los diferentes conocimientos indígenas en diálogo con los conocimientos académicos. Este cambio ha posibilitado la construcción de una práctica pedagógica diferenciada, con perspectiva crítica y liberadora, cuya característica principal es la valorización de los diferentes conocimientos indígenas en su currículo.

Palabras clave: Currículo. Transdisciplinaridad. Escuela Indigena. Roraima. Licenciatura Intercultural. 


\section{INTRODUÇÃO}

O processo de colonização sofrido pelos povos indígenas no Brasil por meio da escola possui dois aspectos importantes, a saber: a sua desvalorização física e a sua desvalorização cultural. A desvalorização cultural envolve, principalmente, a desvalorização dos conhecimentos indígenas no currículo escolar. Durante décadas, por exemplo, a ciência indígena foi marginalizada e desvalorizada no currículo da escola integracionista.

Segundo o professor Maxim Repetto $(2016)^{11}$, ao pensar a construção da Licenciatura Intercultural, houve a necessidade de pensar em princípios teóricos e metodológicos capazes de mudar essa realidade, visto que o momento era propício para isso. Segundo ele, era preciso estabelecer instrumentos pedagógicos que, além de reconhecerem e valorizarem os conhecimentos indígenas no currículo, também pudessem aproximar a prática docente realizada em sala de aula do processo de ensino e aprendizagem ocorrido no dia a dia indígena.

Desse debate se estabeleceu a transdisciplinaridade, a interculturalidade, a dialogia social e o diálogo como princípios teórico-metodológicos e a pesquisa como ferramenta de formação dos professores indígenas na Licenciatura Intercultural da Universidade Federal de Roraima. Neste artigo, por questões de espaço, destacar-se-á apenas os aspectos teóricos e metodológicos da transdisciplinaridade.

O princípio da transdisciplinaridade na Licenciatura Intercultural rompeu com o ensino por disciplina e estabeleceu um processo de ensino e aprendizagem por área de conhecimento, a partir de temas contextuais. Desta forma, o curso não forma um(a) especialista matemático ou um(a)

1 ENTREVISTADO 3 especialista biólogo, por exemplo, mas forma professores(as) em Licenciatura Intercultural com habilitação em uma das três áreas de conhecimento, quais sejam: Ciências Sociais, Ciências da Natureza e Comunicação e Artes.

Essa forma de pensar a formação de professores indígenas mudou a lógica como se tinha pensado e como se formavam professores no âmbito da academia até então. Para alguns dos entrevistados, as lideranças indígenas acreditavam que a formação de professores indígenas deveria contribuir para mudar a realidade do currículo escolar, principalmente no que diz respeito à relação entre conhecimentos indígenas e o conhecimento produzido na academia.

Desta forma, o esforço aqui, além de fazer uma breve exposição teórica sobre o tema, é discorrer sobre alguns aspectos da transdisciplinaridade enquanto princípio teórico e metodológico importantes para a formação de professores indígenas no âmbito da Licenciatura Intercultural da Universidade Federal de Roraima.

\section{METODOLOGIA}

Esse estudo, de cunho qualitativo, é parte da pesquisa de doutoramento do autor. Durante o período da realização da pesquisa (2014-2017) foi possivel alternar período de estudo teórico e análise de documentos com períodos de convivência, entrevistas e observação no campo de pesquisa. Das etapas percorridas, três devem ser descritas nesse texto. A primeira etapa foi a de estudos teórico no Programa de Pós-graduação em Educação: Currículo, na Pontifícia Universidade Católica de São Paulo. A segunda etapa ocorreu na Licenciatura Intercultural da Universidade Federal de Roraima. Na ocasião, o pesquisador participou de encontros em grupo de pesquisa, lecionou alguns temas contextuais como professor colaborador, ministrou palestras, participou de seminários, debates etc. A outra etapa, a fase conclusiva se deu a partir da 
ocasião da qualificação e a defesa da tese de doutorado.

Por se tratar de um artigo com origem em pesquisas realizadas para doutoramento do autor cabe destacar que os entrevistados aqui citados autorizaram a publicação de suas entrevistas bem como de seus respectivos nomes. Cabe destacar ainda que o estudo percorreu e obteve aprovação do Comitê de Ética em Pesquisa da Pontifícia Universidade Católica de São Paulo.

\section{RESULTADOS E DISCUSSÃO}

\section{Aspectos teóricos da transdisciplinaridade}

Em nosso cotidiano profissional é comum ouvir falar sobre multidisciplinaridade, pluridisciplinaridade, interdisciplinaridade e até transdisciplinaridade. Neste texto, vale começar por fazer uma distinção teórica sobre esses termos para, então, voltar o foco para o objeto de estudo, a saber: a transdisciplinaridade no contexto da Licenciatura Intercultural. Segundo Nicolescu (1999b, p. 11), transdisciplinaridade é:

Uma palavra de uma beleza virginal, que ainda não recebeu o desgaste do tempo, espalha-se atualmente por todo mundo como uma explosão de vida e de sentido. Esta palavra, de dificil pronúncia, transdisciplinaridade, conhecida há apenas alguns anos, foi e continua sendo frequentemente confundida com duas outras palavras relativamente recentes: pluridisciplinaridade $e$ interdisciplinaridade.

De forma muito genérica, pode-se afirmar que a transdisciplinaridade propõe

2 Segundo Souza (2009), a prática docente é apenas uma das dimensões da prática pedagógica. A prática docente está interconectada com a prática gestora, a prática discente e a prática epistemológica. Isso significa que a prática pedagógica inclui a prática docente, mas a ela não se reduz. a superação do modo de pensar dicotômico (sujeito-objeto, parte-todo, razão-emoção etc.), proveniente da visão sistematizada pelo filósofo francês René Descartes (1596-1650).

A forma transdisciplinar de pensar e organizar as coisas vai contra princípios que, durante muito tempo, fundamentaram as organizações sociais, culturais e educacionais. Tais princípios dominantes justificam que a organização da academia e a produção do conhecimento baseiem-se na recomendação de Descartes (1996, p. 23), segundo a qual, quando se está ante um fenômeno complexo, se deve "dividir cada uma das dificuldades [...] em tantas parcelas quantas fosse possivel e necessário para melhor resolvê-las".

Esse é o princípio da fragmentação e, como consequência, a prática pedagógica ${ }^{2}$ tendeu a organizar-se hegemonicamente nos moldes da disjunção dos pares binários: simples-complexo, parte-todo, local-global, unidade-diversidade, particular-universal etc. Em contrapartida, cristalizou-se a subdivisão do conhecimento em áreas, institutos e departamentos, cada qual delimitado pelas suas fronteiras epistemológicas.

$\mathrm{Na}$ universidade, cada instituto ou departamento passou a organizar seus respectivos cursos por meio de listas de diferentes disciplinas: são as grades curriculares que, na prática, funcionam como esquemas que podem impedir o fluxo de relações existentes entre as disciplinas e áreas de conhecimento, vigorando o princípio da fragmentação, da divisão, da simplificação, da redução. A consequência desse tipo de estrutura é a fragmentação e a posterior descontextualização da prática docente.

Essa visão descontextualizada e simplificadora, difundidapela ciênciamoderna, tornou-se hegemônica ao longo dos últimos quatrocentos anos e manteve latente a questão da complementaridade dos pares binários. A partir das últimas décadas, no entanto, o que 
permanecia implícito se manifestou com força significativa e se transformou em principios científicos, evolução acontecida no próprio seio da ciência moderna, nascendo, assim, a transdisciplinaridade.

$\mathrm{Na}$ atualidade, $\mathrm{o}$ termo transdisciplinaridade sugere muitos significados, desde aqueles capazes de incitar atraentes movimentos reflexivos, investigativos, até reações de fortes resistências e desconfianças, principalmente se considerarmos a perspectiva polissêmica que a palavra é capaz de inspirar.

(2000), a acordo com Rodrigues
diferente da multidisciplinaridade e da interdisciplinaridade. A autora afirma que a multidisciplinaridade ou pluridisciplinaridade trata do estudo de um mesmo objeto por várias disciplinas; não há necessidade de integração entre elas, uma vez que cada qual concorre com seus conhecimentos específicos no estudo de determinado assunto, podendo, no máximo, resultar em certa organicidade de apresentação dos resultados ou de contribuições. São visiveis os níveis de cooperação das diferentes disciplinas e, também, a peculiaridade produzida pela consequente orientação dos conhecimentos envolvidos naquele estudo.

A interdisciplinaridade, diferentemente da pluri ou da multidisciplinaridade, propõe a troca de informações e de conhecimentos entre disciplinas, mas, fundamentalmente, transfere métodos de uma disciplina para outras. Por exemplo: os métodos da física nuclear podem auxiliar na cura do câncer, na engenharia de alimentos ou de remédios. Corresponde a um espectro mais ampliado de ação, alcançando um processo de interação entre disciplinas capaz de promover a conjugação de conhecimentos que elevem os níveis de saber.

A interdisciplinaridade possibilita não só a fecunda interlocução entre as áreas do conhecimento como também constitui uma estratégia importante para que elas não se estreitem nem se cristalizem no interior de seus respectivos domínios; favorece o alargamento e a flexibilização dos conhecimentos, disponibilizando-os em novos horizontes do saber.

A perspectiva interdisciplinar, segundo Rodrigues (2000), não fere a especificidade das profissões e tampouco seus campos de especialidade. Muito pelo contrário, requer a originalidade e a diversidade dos conhecimentos que produzem e sistematizam acerca de determinado objeto, de determinada prática, permitindo a pluralidade de contribuições para compreensões mais consistentes deste mesmo objeto, desta mesma prática.

Por esta forma, a interdisciplinaridade não pretendea unidade deconhecimentos, mas a parceria e a mediação dos conhecimentos, na criação de saberes. Podemos arriscar ver nela uma mediação para a transdisciplinaridade. Jurjo Torres Santomé apresenta esses termos de uma forma hierárquica, com níveis de colaboração e integração entre as disciplinas. Essa proposta, segundo o referido autor, foi inicialmente levantada por Jean Piaget. Desta forma, de acordo com Santomé (1998, p. 70), pode-se assim compreender:

1. Multidisciplinaridade. O nivel inferior de integração. Ocorre quando, para solucionar um problema, busca-se informação e ajuda em várias disciplinas, sem que tal interação contribua para modificá-las ou enriquecê-las. Esta costuma ser a primeira fase da constituição de equipes de trabalho interdisciplinar, porém não implica em que necessariamente seja preciso passar a níveis de maior cooperação.

2. Interdisciplinaridade. Segundo nivel de associação entre disciplinas, em que a cooperação entre várias disciplinas provoca intercâmbios reais; isto é, existe verdadeira reciprocidade nos intercâmbios e, consequentemente, enriquecimentos mútuos.

3. Transdisciplinaridade. É a etapa superior de integração. Trata-se da construção de um sistema total, sem fronteiras sólidas entre as discipli- 
nas, ou seja, de "uma teoria geral de sistemas ou de estruturas, que inclua estruturas operacionais, estruturas de regulamentação e sistemas probabilísticos, e que una estas diversas possibilidades por meio de transformações reguladas e definidas".

\section{(2)}

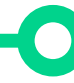

Basarab Nicolescu (1999b, p. 10-11) apresenta um entendimento similar ao de Santomé. Ao discorrer sobre o termo transdisciplinaridade, o autor nos ajuda nessa reflexão teórica sobre o tema, ao afirmar que:

pluridisciplinaridade diz respeito ao estudo de um objeto de uma mesma e única disciplina por várias disciplinas ao mesmo tempo. Por exemplo, um quadro de Giotto pode ser estudado pela ótica da história da arte, em conjunto com a da física, da química, da história das religiões, da história da Europa e da geometria. Ou ainda, a filosofia marxista pode ser estudada pelas óticas conjugadas da filosofia, da fisica, da economia, da psicanálise ou da literatura. Com isso, o objeto sairá assim enriquecido pelo cruzamento de várias disciplinas. $O$ conhecimento do objeto em sua própria disciplina é aprofundado por uma fecunda contribuição pluridisciplinar. A pesquisa pluridisciplinar traz um algo a mais à disciplina em questão (a história da arte ou a filosofia, em nossos exemplos), porém este "algo a mais" está a serviço apenas desta mesma disciplina. Em outras palavras, a abordagem pluridisciplinar ultrapassa as disciplinas, mas sua finalidade continua inscrita na estrutura da pesquisa disciplinar. A interdisciplinaridade tem uma ambição diferente daquela da pluridisciplinaridade. Ela diz respeito à transferência de métodos de uma disciplina para outra. Podemos distinguir três graus de interdisciplinaridade: a) um grau de aplicação. Por exemplo, os métodos da física nuclear transferidos para a medicina levam ao aparecimento de novos tratamentos para o câncer; b) um grau epistemológico. Por exemplo, a transferência de métodos da lógica formal para o campo do direito produz análises interessantes na epistemologia do direito; c) um grau de geração de novas disciplinas. Por exemplo, a transferência dos métodos da matemática para o campo da física gerou a física matemática; os da física de partículas para a astrofisica, a cosmologia quântica; os da matemática para os fenômenos meteorológicos ou para os da bolsa, a teoria do caos; os da in- formática para a arte, a arte informática. Como a pluridisciplinaridade, a interdisciplinaridade ultrapassa as disciplinas, mas sua finalidade também permanece inscrita na pesquisa disciplinar. Pelo seu terceiro grau, a interdisciplinaridade chega a contribuir para o big-bang disciplinar.

Segundo oautor, atransdisciplinaridade, como o prefixo "trans" indica, diz respeito àquilo que está ao mesmo tempo entre as disciplinas, através das diferentes disciplinas e além de qualquer disciplina. Seu objetivo é a compreensão do mundo presente, para o qual um dos imperativos é a unidade do conhecimento. Esse é o conceito de transdisciplinaridade que se adotou neste estudo.

\section{Os tratados internacionais sobre transdisciplinaridade}

Pela sua importância na atualidade, a transdisciplinaridade é um tema discutido em inúmeros eventos internacionais, que geraram documentos importantes, dentre os quais vale a pena destacar os que melhor contribuem para o debate neste texto.

O primeiro é o Congresso Ciência e Tradição: Perspectivas Transdisciplinares para o século XXI (1991), organizado pela UNESCO, em Paris, de 2 a 6 de dezembro de 1991. Esse congresso gerou um documento, intitulado Ciência e Tradição: Perspectivas Transdisciplinares para o século XXI, que muito contribuiu para a definição conceitual e da metodologia transdisciplinar. Desse documento é importante destacar alguns tópicos:

3. Uma das revoluções conceituais deste século veio, paradoxalmente, da ciência, mais particularmente da fisica quântica, que fez com que a antiga visão da realidade, com seus conceitos clássicos de determinismo, que ainda predominam no pensamento político e econômico, fosse 
explodida. Ela deu à luz a uma nova lógica, correspondente, em muitos aspectos, a antigas lógicas esquecidas. Um diálogo capital, cada vez mais rigoroso e profundo, entre a ciência e a tradição pode então ser estabelecido a fim de construir uma nova abordagem científica e cultural: a transdisciplinaridade.

4. A transdisciplinaridade não procura construir sincretismo algum entre a ciência e a tradição: a metodologia da ciência moderna é radicalmente diferente das práticas da tradição. A transdisciplinaridade procura pontos de vista a partir dos quais seja possivel torná-las interativas, procura espaços de pensamento que as façam sair de sua unidade, respeitando as diferenças, apoiando-se especialmente numa nova concepção da natureza.

5. Uma especialização sempre crescente levou a uma separação entre a ciência e a cultura, separação que é a própria característica do que podemos chamar de "modernidade" e que só fez concretizar a separação sujeito-objeto que se encontra na origem da ciência moderna. Reconhecendo o valor da especialização, a transdisciplinaridade procura ultrapassá-la recompondo a unidade da cultura e encontrando o sentido inerente à vida.

6. Por definição, não pode haver especialistas transdisciplinares, mas apenas pesquisadores animados por uma atitude transdisciplinar. Os pesquisadores transdisciplinares imbuídos desse espírito só podem se apoiar nas diversas atividades da arte, da poesia, da filosofia, do pensamento simbólico, da ciência e da tradição, elas próprias inseridas em sua própria multiplicidade e diversidade. Eles podem desaguar em novas liberdades do espírito graças a estudos trans-históricos ou transreligiosos, graças a novos conceitos como transnacionalidade ou novas práticas transpolíticas, inaugurando uma educação e uma ecologia transdisciplinares.

7. O desafio da transdisciplinaridade é gerar uma civilização, em escala planetária, que, por força do diálogo intercultural, se abra para a singularidade de cada um e para a inteireza do ser.

Esse documento, que pode ser considerado o segundo documento sobre transdisciplinaridade em congressos internacionais, vem propondo o diálogo da ciência acadêmica, dita científica, com diferentes lógicas, epistemologias, culturas, tradições. Esse é um aspecto importante da transdisciplinaridade, posto que a escola integracionista nunca tenha garantido essa abertura no que tange aos diferentes conhecimentos indígenas em seu currículo.

Deve-se destacar ainda o I Congresso Mundial da Transdisciplinaridade, organizado pelo CIRET - Centro Internacional de Pesquisas e Estudos Transdisciplinares (que tem sede em Paris), em parceria com a UNESCO, ocorrido em Arrábida (Portugal), no período de 2 a 6 de novembro de 1994.

Esse Congresso produziu um documento chamado Carta da Transdisciplinaridade (1994), que foi assinado por 62 participantes, de 14 países. Desse documento vale destacar algumas passagens dos 14 artigos, que avançam e muito podem contribuir com o presente estudo. Esse documento é importante, pois nos apresenta o conceito de diferentes realidades, regidas por diferentes leis.

Em tempos passados, a ciência, além de não admitir diferentes níveis de realidade, ainda acreditava que a natureza era regida pelas mesmas leis. No entanto, durante os últimos séculos, com novas descobertas principalmente, a partir das descobertas da física quântica -, se estabeleceu a visão transdisciplinar da natureza e, ao se fazer isso, permitiu-se enxergar a natureza a partir de diferentes niveis de realidade e formular leis específicas que regem a natureza em realidades específicas.

Pensar transdisciplinarmente a natureza e suas realidades é um exercício bastante complexo e desafiador. Apesar disso, devemos assumir o desafio de torná-la pedagogicamente compreensivel, conservando 0 conceito principal. Para fazer isso, precisamos compreender que a revolução científica, ocorrida, principalmente, no campo da física quântica no último século, nos ensinou a olhar a natureza e compreendêla a partir de diferentes níveis de realidades e leis específicas a cada realidade.

$\mathrm{Na}$ realidade visível a olho nu, por exemplo, qualquer objeto, ao mover-se de um ponto A para um ponto $B$, precisa fazer 0 
percurso de forma contínua. Se isso é verdade, então essa é uma lei que rege o deslocamento de todos os objetos nesse nível e nessa realidade. Até pouco tempo atrás se acreditava que essa mesma lei também regesse o mundo atômico, mas estudos e descobertas da física quântica, além de nos revelar uma realidade totalmente diferente daquela que enxergamos, ainda nos revelaram que as leis que regem essa realidade nem sempre são as mesmas que regem a realidade visível.

O físico alemão Max Planck (1858-1947), ao investigar a irradiação atômica (quando há "perda" de elétrons de um átomo), observou que os elétrons, ao deslocarem-se de uma camada atômica para outra (ponto A ao ponto B), não o faziam da mesma forma como os objetos fazem na realidade visível ao olho nu, na realidade macro. Ele observou que os elétrons "desapareciam" em uma camada atômica e automaticamente apareciam em outra camada, sem necessariamente terem que percorrer continuamente do ponto A até o ponto $B$, como ocorre na realidade macro. Daí se estabeleceu a lei segundo a qual se diz que diferentes realidades são regidas por diferentes leis.

A Carta da Transdisciplinaridade (1994), em seu artigo 2, afirma que "o reconhecimento da existência de diferentes níveis de realidade, regidos por lógicas e leis diferentes, é inerente à atitude transdisciplinar". Quanto à definição do conceito, os artigos 3, 5, 6 e 7 da referida Carta devem ser destacados:

Artigo 3: A Transdisciplinaridade é complementar à abordagem disciplinar; ela faz emergir novos dados a partir da confrontação das disciplinas que os articulam entre si; ela nos oferece uma nova visão da Natureza e da Realidade. A transdisciplinaridade não procura o domínio de várias disciplinas, mas a abertura de todas as disciplinas ao que as une e as ultrapassa.

Artigo 5: A visão transdisciplinar é resolutamente aberta na medida em que ela ultrapassa o campo das ciências exatas devido ao seu diálogo e [à] sua reconciliação não somente com as ciências humanas, mas também com a arte, a literatura, a poesia e a experiência espiritual.

Artigo 6: Com relação à interdisciplinaridade e à multidisciplinaridade, a transdisciplinaridade é multirreferencial e multidimensional. Embora levando em conta os conceitos de tempo e de história, a transdisciplinaridade não exclui a existência de um horizonte transhistórico.

Artigo 7: A transdisciplinaridade não constitui nem uma nova religião, nem uma nova filosofia, nem uma nova metafisica, nem uma ciência das ciências.

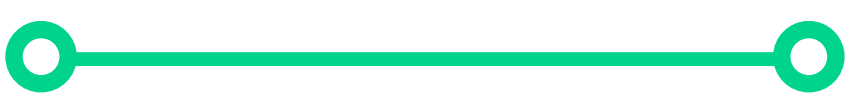

A atitude do pesquisador e do sujeito transdisciplinar também é definida amplamente em vários dos artigos da Carta da Transdisciplinaridade (1994)::

Artigo 9: A transdisciplinaridade conduz a uma atitude aberta em relação aos mitos, às religiões e àqueles que os respeitam num espírito transdisciplinar.

Artigo 10: Não existe um lugar cultural privilegiado de onde se possam julgar as outras culturas. A abordagem transdisciplinar é ela própria transcultural.

Artigo 11: Rigor, abertura e tolerância são características fundamentais da atitude e da visão transdisciplinar. O rigor na argumentação, que leva em conta todos os dados, é a melhor barreira contra possiveis desvios. A abertura comporta a aceitação do desconhecido, do inesperado e do imprevisível. A tolerância é o reconhecimento do direito às ideias e verdades contrárias às nossas

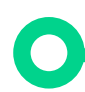

Todos os artigos da Carta da Transdisciplinaridade aqui citados, de um modo ou outro, destacam características da atitude transdisciplinar. É essa "atitude aberta em relação aos mitos, às religiões [...]" etc. que interessa para formação de professores indígenas na Licenciatura Intercultural e também para a educação escolar indígena da atualidade.

Pode-se afirmar, no entanto, que uma atitude transdisciplinar com tais características depende do domínio 
conceitual sobre transdisciplinaridade. É preciso entender conceitualmente o que é transdisciplinaridade para poder ter uma metodologia transdisciplinar e uma postura transdisciplinar.

\section{A transdisciplinaridade no contexto da licenciatura intercultural-UFRR}

Pensar e agir transdisciplinarmente na sala de aula da Licenciatura Intercultural tem como objetivo primeiro a compreensão do mundo presente e do contexto social, político, econômico e cultural em que vivem os índios na atualidade; no entanto, não se propõe fazer isso de forma fragmentada, como se costumava fazer anteriormente, mas, de forma uniforme e sistêmica, sempre partindo da realidade dos povos indígenas.

Paraa professora Fabiola Carvalho(2017) ${ }^{1}$ que atua na área de habilitação das Ciências da Natureza na Licenciatura Intercultural e uma das entrevistadas para esta pesquisa, esse princípio é importantíssimo e válido para a formação de professores indígenas, mas o domínio conceitual e a implementação metodológica em sala de aula dependem da autoformação tanto do professor formador quanto do estudante indígena, visto que não há nenhum tema contextual voltado exclusivamente para a abordagem conceitual do que seja transdisciplinaridade ou sua metodologia. A esse respeito, o professor Maxim Repetto afirma:

[...] na verdade, foram aparecendo esses temas e tivemos que estudar eles, né?; ai encontramos aquelas cartas da transdisciplinaridade, dos primeiros encontros na Europa, que promoveram a transdisciplinaridade e nos parecia interessante essa perspectiva de ver que os problemas e o mundo é [sic] multidimensional e que precisam de respostas múltiplas e, aí, o transdisciplinar ajudava. Então, um pouco que pensamos e eu acho que nos primeiros anos a gente conseguia fazer mais, talvez, do que hoje, porque a gente conseguia ter mais de um professor em sala de aula e isso era muito bacana. Então, tínhamos aula que era [sic] professores de formação diferente mais os parentes, que eram de vários povos, e temas que chamavam explicações diferentes $e$ eu imaginava assim as aulas: mais do que uma aula para repassar informações, deveria ser uma aula de reflexão, de debates, de confrontos $e$ ideias mesmo, né? (REPETTO, 201

Pode-se observar, a partir das declarações acima, que as aulas foram pensadas para ocorrerem com a presença de mais de um professor em sala de aula. Se assim fosse, em um determinado tema contextual, por exemplo, os professores juntamente com os estudantes trariam para a reflexão em sala de aula as problemáticas que afetam diretamente as comunidades indígenas através dos temas contextuais. Nesse caso, segundo a proposta pedagógica do curso, tanto os professores formadores quanto os estudantes indigenas assumiriam papel relevante nos debates teóricos e nas reflexões realizadas sobre tais problemáticas.

Novos problemas sociais têm surgido ao longo desse processo histórico, tais como problemas internos nas comunidades, impacto nas estruturas sociais, impacto no sistema produtivo e de vida, etc. Neste novo contexto, os professores $e$ lideranças indígenas discutem o papel da escola e se empenham na construção de novas estratégias, cristalizadas por meio de projetos políticos, pedagógicos e culturais.

Nesta construção, acentua-se a importância do papel do professor indígena, que atua como problematizador nas escolas e nas comunidades $e$ como catalisador das soluções propostas. A sua atuação pedagógica e social deve estar, deste modo, comprometida com os interesses de sua comunidade, com a valorização da cultura e com a produção de novos conhecimentos.

Desta perspectiva, o Curso de Licenciatura Intercultural para professores Indígenas tem o objetivo de construir diversas ferramentas, dentre elas o princípio da transdisciplinaridade, para que o 
professor possa colaborar com a comunidade na definição de prioridades e na análise das problemáticas. (CARVALHO; FERNANDES; REPETTO, 2008, p. 58, grifos meus)

A análise das "problemáticas" locais e a busca por soluções é importante nesse curso e, por isso, sua análise e reflexões deveria ser subsidiada pelos conhecimentos teóricos próprios da academia em diálogo com os diferentes conhecimentos indígenas presentes por meio dos estudantes oriundos dos diferentes povos indígenas. A esse respeito, está explícito na proposta pedagógica do curso:

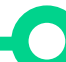

[...] a escola indígena deve planejar a formação de seus alunos a partir dos projetos específicos de cada comunidade e o professor licenciado deverá estar preparado para exercer a docência nestas escolas. Para tanto, o currículo, em vez de estar organizado pelo tradicional sistema de disciplinas estanques, terá uma abordagem transdisciplinar, que é relevante para o entendimento das questões locais [...]. (Ibidem, p. 51-52, grifos meus)

A formação de professores indigena a partir de uma perspectiva transdisciplinar não se propunha a oferecer "apenas" oficinas disciplinares - por exemplo, oficina de matemática, biologia, história, língua portuguesa etc. -, como ocorre em alguns casos hoje, mas a abordar os temas contextuais a partir de diferentes perspectivas ou de distintas realidades.

Interessa para a educação escolar indígena da atualidade essa abertura para o diálogo que a transdisciplinaridade propõe. Para o debate em sala de aula interessa o diálogo entre a ciência acadêmica e as diferentes lógicas, epistemologias, culturas e tradições da atitude transdisciplinar, pois, isso possibilitaria identificar e reconhecer os diferentes conhecimentos indígenas e sua valorização no currículo de formação no âmbito da universidade.

É importante observar que não se propunha, em momento algum, uma sobreposição dos conhecimentos indígenas sobre os conhecimentos acadêmicos ou científicos, mas, somente, o diálogo (numa perspectiva freireana) entre ambos. Parece óbvio afirmar, por esta forma, que os conhecimentos acadêmicos têm muito a contribuir com a resolução de problemas sociais, de saúde, ambientais etc. muito presentes no seio das comunidades indígenas na atualidade.

\section{CONSIDERAÇÕES FINAIS}

O pensamento transdisciplinar, uma vez compreendido e colocado em prática, pode mudar a relação integracionista de verdade e mentira estabelecida entre os conhecimentos acadêmicos e os conhecimentos indígenas. Para isso, na Licenciatura Intercultural, se propôs que os temas contextuais fossem problematizados e estudados com o auxílio de conhecimentos oriundos de diferentes áreas do conhecimento acadêmico, em constante diálogo com os conhecimentos indígenas.

No entanto, as observações in loco revelaram que alguns professores formadores da Licenciatura Intercultural, dentre os quais professores efetivos, substitutos e colaboradores, transformaram a abordagem transdisciplinar dos temas contextuais em oficinas disciplinares de sua área de formação.

A ideia implícita nos temas contextuais, problematizados, discutidos criticamente entre os participantes do processo de ensino e aprendizagem era fornecer as ferramentas teóricas e metodológicas necessárias à produção de novose diferentes conhecimentos teóricos e práticos para melhor atender à educação escolar e as comunidades indígenas em suas especificidades.

Além disso, o processo de ensino 
e aprendizagem indígena é outro aspecto importante que se poderia contemplar com esse princípio. Sabe-se que nas sociedades indígenas, de forma geral, valoriza-se a indissociabilidade do aprender e do fazer no processo formativo da criança. Sendo assim, o processo de ensino e aprendizagem por temas contextuais, por área de conhecimento (e não por disciplinas), com uma abordagem transdisciplinar, deveria ser uma proposta alternativa à forma compartimentada do processo de ensino e aprendizagem e à fragmentação dos objetos estudados na escola de cunho integracionista.

A professora Fabiola Carvalho (2017), afirmou que "adotar a transdisciplinaridade como princípio teórico e metodológico na educação escolar indígenas é um desafio autoformativo tanto para quem ensina quanto para quem aprende". Tomem-se como exemplo os professores formadores da Licenciatura Intercultural, mesmo aqueles que possuem doutorado, vêm de uma formação disciplinar para atuarem em um curso com perspectiva transdisciplinar, por área de conhecimento.

O formando indígena, por sua vez, adquire uma formação com perspectiva transdisciplinar, por área de conhecimento, para atuar em uma escola indigena que ainda se organiza disciplinarmente. Daí a importância de adquirir, durante o seu processo de formação, os saberes (conceitual, procedimental e atitudinal) referentes ao princípio da transdisciplinaridade, pois somente de posse desses saberes o docente, seja formador ou formando, poderia ser e agir transdisciplinarmente.

\section{REFERÊNCIAS}

CARVALHO, F. A.; FERNANDES, M. L.; REPETTO, M. (Orgs.). Projeto Político-Pedagógico da Licenciatura Intercultural. Boa Vista, RR: Ed. UFRR, 2008.

CARVALHO, F. Entrevista concedida a Geisel
Bento Julião. Boa Vista, 26 jan. 2017.

CARTADATRANSDISCIPLINARIDADE. Documento Final, 1994. Disponível em: <http://cetrans. com.br/wp-content/uploads/2014/09/CARTADA-TRANSDISCIPLINARIDADE1.pdf>. Acesso em: 2 ago. 2016.

CIÊNCIA E TRADIÇÃO: PERSPECTIVAS TRANSDISCIPLINARES PARA O SÉCULO XXI [CONGRESSO]. Comunicação Final, 1991. Disponível em: <http://www.cetrans.com. $\mathrm{br} /$ textos/documentos/congresso-cienciatradicao.pdf>. Acesso em: 2 ago. 2016.

DESCARTES, R. Discurso do método. São Paulo: Martins Fontes, 1996.

NICOLESCU, B. 0 manifesto da transdisciplinaridade. São Paulo: Trion, 1999a.

REPETTO, M. Entrevista concedida a Geisel Bento Julião. Boa Vista, 01 dez. 2016.

RODRIGUES, $M$. L. Caminhos da transdisciplinaridade: fugindo às injunções lineares. In: NEMESS, PUC-SP. 2000. Disponível em: $\quad$ <ttp://www.pucsp.br/nemess/links/ artigos/marialucia3.htm>. Acesso em: 20 de jul. 2016.

SANTOMÉ, J. T. Globalização e interdisciplinaridade. Porto Alegre: Artmed, 1998.

SOUZA, J. F. Prática pedagógica e formação de professores. José Batista Neto; Eliete Santiago (Orgs.). Recife, PE: Ed. Universitária UFPE, 2009. 